\title{
Calibration of a multi-species model for chlorophyll estimation in seedlings of Neotropical tree species using hand-held leaf absorbance meters and spectral reflectance
}

\author{
Daniela Vieira Silva ${ }^{(1)}$, \\ Letícia Dos Anjos (2), \\ Ediófila Brito-Rocha ${ }^{(2)}$, \\ Andrea Carla Dalmolin ${ }^{(2)}$, \\ Marcelo S Mielke ${ }^{(2)}$
}

\begin{abstract}
The aim of the present study was to calibrate a multi-species model for assessing leaf chlorophyll content in seedlings of six Neotropical rainforest tree species. Two hand-held chlorophyll absorbance meters (SPAD-502 and ClorofiLog) and the chlorophyll normalized difference leaf reflectance index $\left(\mathrm{ND}_{705}\right)$ were tested. Measurements of leaf absorbance and reflectance, contents of chlorophyll a ( $\mathrm{Chl} a$ ), chlorophyll b ( $\mathrm{Chl} b$ ), and total chlorophyll (Chl $t$ ), leaf area (LA), and leaf mass per area (LMA) were performed on fully expanded leaves. A total of 200 leaves were used for the calibration of the multiplespecies model. The relative root mean square calibration errors $\left(\mathrm{RMSE}_{\mathrm{c}}, \%\right)$ were calculated based on estimated chlorophyll values for multiple-species models and on measured values for each of the six species. The average values of LA varied between 14.2 and $29.5 \mathrm{~cm}^{-2}$, LMA between 34.8 and $98.9 \mathrm{~g} \mathrm{~m}^{-2}$, and $\mathrm{Chl} t$ between 3 and $815 \mathrm{mg} \mathrm{m}^{-2}$. For all indices, the highest values of the coefficients of determination $\left(R^{2}\right)$ were observed for Chl $a\left(R^{2} \geq 0.91\right)$, followed by Chl $t\left(R^{2} \geq 0.89\right)$ and $\mathrm{Chl} b\left(R^{2} \geq 0.82\right)$. The highest values of $R^{2}$ were obtained for $\mathrm{ND}_{705}\left(R^{2} \geq 0.86\right)$ followed by SPAD-502 $\left(R^{2} \geq 0.83\right)$ and ClorofiLog $\left(R^{2} \geq 0.82\right)$. The present study showed that ClorofiLog and SPAD-502 indices could be safely interconverted by a simple linear regression model $\left(R^{2}=0.98\right)$. RMS $\varepsilon_{c}$ values were lower than $20 \%$, which confirmed the feasibility of the multi-species model for estimating the chlorophyll content using hand-held chlorophyll absorbance meters and leaf reflectance.
\end{abstract}

Keywords: Chlorophyll Normalized Difference Index, Hand-held Chlorophyll Absorbance Meters, Leaf Reflectance, Neotropical Tree Species ness of plants and ecosystems (Pettorelli et al. 2005, Grace et al. 2007).

Spectrophotometry is the most conventional and precise technique for the determination of leaf chlorophyll content. It requires tissue homogenization with an oror dimethyl sulfoxide (DMSO), and a spectrophotometer for the direct quantification of pigments (Lichtenthaler 1987, Wellburn 1994). Nonetheless, this technique is destructive and usually has to be performed under laboratory conditions. Other disadvantages of this technique are the low ganic extraction solvent, such as acetone

$\square$ (1) Departamento de Ciências Agrárias e Ambientais, Universidade Estadual de Santa Cruz, Rodovia Jorge Amado km 16, llhéus, Bahia (Brazil); (2) Departamento de Ciências Biológicas, Universidade Estadual de Santa Cruz, Ithéus, Bahia (Brazil)

@ Marcelo S Mielke (msmielke@uesc.br)

Received: Jul 30, 2015 - Accepted: Jan 17, 2016

Citation: Vieira Silva D, Dos Anjos L, Brito-Rocha E, Dalmolin AC, Mielke MS (2016). Calibration of a multi-species model for chlorophyll estimation in seedlings of Neotropical tree species using hand-held leaf absorbance meters and spectral reflectance. iForest 9: 829834. - doi: 10.3832/ifor1785-009 [online 2016-05-17]

Communicated by: Silvano Fares number of samples that can be processed per day and the necessity of transporting leaves from the field to the laboratory, which could interfere with the results, since more delicate leaves may suffer dehydration and pigment oxidation after harvesting.

With the development of optical instrumentation, the estimation of chlorophyll content has become easier, faster, nondestructive, and can be performed in the field. Currently, with the use of hand-held chlorophyll meters and portable reflectometers, it is possible to analyze a large number of samples in a single day and to measure the same leaf several times as it grows and develops. Hand-held chlorophyll meters are often calibrated to a single index and measure the absorption of electromagnetic radiation in the red and infrared regions (Markwell et al. 1995). Red light is strongly absorbed by chlorophyll, whereas near-infrared light is used as an internal reference wavelength to adjust for differences in leaf structure. Conversely, portable reflectometers measure the radiation reflected by the leaf at a wide range of wavelengths (Richardson et al. 2002, Sims \& Gamon 2002). Methods based on the reflection of electromagnetic radiation by leaves originated from remote sensing 
technology and are based on vegetation indices (Gitelson \& Merzlyak 1994, Gamon \& Surfus 1999, Richardson et al. 2002, Sims \& Gamon 2002, Blackburn 2007). Conceptually, vegetation indices are mathematical transformations of spectral bands used to estimate the contribution of vegetation in multispectral observations. The equations of most vegetation indices are mainly derived from bands of red and near infrared, such as the normalized difference vegetation index (NDVI) at an ecosystem scale (Pettorelli et al. 2005, Blackburn 2007), or the chlorophyll normalized difference index $\left(\mathrm{ND}_{705}\right)$ at a leaf scale (Gitelson \& Merzlyak 1994, Richardson et al. 2002).

Hand-held chlorophyll meters and portable reflectometers are more convenient than extraction methods because they offer a more rapid, efficient, and nondestructive assessment of the leaf chlorophyll content. Nevertheless, optical methods also have limitations. First, they do not provide absolute chlorophyll content, but only relative indices that express the relative chlorophyll content (Richardson et al. 2002, Blackburn 2007). Thus, the indices need to be previously calibrated with a more precise extraction method in the laboratory to provide absolute values of chlorophyll content. There are several mathematical models available in the literature for the calibration of hand-held absorbance chlorophyll meters. However, most of the available models are species specific and developed either for crop species (Steele et al. 2008, Schlemmer et al. 2013, Casa et al. 2015) or temperate and sub-tropical forests species (Cate \& Perkins 2003, Van Den Berg \& Perkins 2004, Pinkard et al. 2006, Hawkins et al. 2009). There are limited studies on the calibration of nondestructive methods for estimating leaf chlorophyll content in tropical tree species (Marenco et al. 2009, Coste et al. 2010, Mielke et al. 2010). Additionally, most of the available models are restricted to an estimation of total chlorophyll ( $\mathrm{Chl} t$ ) (Marenco et al. 2009, Coste et al. 2010, Mielke et al. 2012) and there are limited models for the estimation of chlorophyll a $(\mathrm{Chl} a)$ and $\mathrm{b}$ (Chl $b$ - Richardson et al. 2002, Mielke et al. 2010). Estimation of $\mathrm{Chl} a$ and $b$ is important for the calculation of the ratio $\mathrm{Chl} a / b$, which is an indicator of photosynthetic performance (Kitajima \& Hogan 2003) and frequently used in studies on light acclimation

Tab. 1 - List of the six Neotropical tree species with their scientific names, family and type of leaves. (1): Only for seedlings. Adults of this species have compound leaves.

\begin{tabular}{lll}
\hline Scientific name & Family & Leaves \\
\hline Brosimum rubescens Taub. & Moraceae & Simple \\
Calophyllum brasiliense Cambess. & Calophyllaceae & Simple \\
Cytharexyllum myrianthum Chamiáo & Verbenaceae & Simple \\
Eriotheca macrophylla $($ K. Schum.) A. Robyns & Bombacaceae & Simple ${ }^{(1)}$ \\
Inga capitata Desv. & Fabaceae & Compound \\
Tapirira guianensis Aublet. & Anacardiaceae & Compound \\
\hline
\end{tabular}

programs (Grossnickle 2012, poe et al. 2014). Another limitation of optical methods refers to the physical properties of instruments that can result in nonlinear relationships between chlorophyll indices and absolute chlorophyll content (Richardson et al. 2002, Sims \& Gamon 2002, Uddling et al. 2007, Steele et al. 2008). For instance, high leaf mass per area (LMA) may lead to the underestimation of chlorophyll content because high leaf thickness is usually associated with high mutual chloroplast shading and high overlapping of optical properties from distinct cell constituents that can affect the reflectance captured by the instrument (Kokaly et al. 2009). Heterogeneity in chlorophyll distribution may also create bias, from different leaf anatomical structures in distinct species, leaf developmental stages, and leaf vein networks. Finally, hand-held absorbance chlorophyll meters may lose sensitivity at high chlorophyll contents because of (Steele et al. 2008). Therefore, the development of standard models that account for different leaf morphologies to be applied to different species and environmental conditions is necessary.

Estimation of leaf chlorophyll content of tree seedlings in areas of high biodiversity, such as tropical rainforests, that contain and anatomical structures, still represents a challenge for researchers. Coste et al. (2010) developed a homographic model for the calibration of the SPAD-502 index to estimate chlorophyll content in a group of 13 Neotropical tree species with a wide range of LMA and chlorophyll contents. The developed homographic model was more accurate than the linear, polynomial, and exponential models and provided acchlorophyll content. However, Coste et al. (2010) did not calibrate their model for other chlorophyll indices, and did not test Therefore, we conducted this study to test whether the multi-species model proposed by Coste et al. (2010) is suitable for the calibration of the hand-held chlorophyll absorand of the leaf reflectance index $N_{705}$ (Gitelson \& Merzlyak 1994) for the estima- tion of $\mathrm{Chl} a, b$, and $t$ in the leaves of seedlings at the nursery stage of six Neotropical rainforest tree species. saturation of absorption in the red range many species with different biochemical curate estimates at high and low values of the model during initial tree development. bance meters SPAD-502 and ClorofiLog,

\section{Materials and methods}

Data were collected from seedlings of six Neotropical rainforest tree species representing six different botanical families (Tab. 1). The seedlings were grown under $50 \%$ artificial shading, in the nursery of Floresta Viva Institute (http://www.florestavi va.org.br), Serra Grande, Uruçuca, Bahia, (Brazil). When seedlings were 2-4-months old, they were transported to the Plant Physiology Laboratory of the Universidade Estadual de Santa Cruz (UESC), Ilhéus, Bahia (Brazil), shortly before measurements. In the laboratory, we collected 30 to 37 fully expanded leaves from each species, with a total of 200 leaves. All the leaves collected had preserved edges and no sign of herbivory or disease symptoms. We measured the leaf absorbance, leaf reflectance, $C h l a, b$, and $t$ contents, leaf area (LA), and leaf mass per area (LMA).

Leaf absorbance and reflectance were measured immediately after their collection. Leaf absorbance was measured using the handheld chlorophyll absorbance meters ClorofiLog ${ }^{\oplus}$ (Falker, Porto Alegre, Brazil) and SPAD-502 ${ }^{\circledR}$ (Minolta Inc., Osaka, Japan), for the determination of the Falker chlorophyll index $(\mathrm{FCl})$ and the SPAD index (SPADi), respectively. Leaf reflectance of the adaxial leaf surface was measured with an USB4000-UV-VIS spectrometer using a LS-1 tungsten-halogen light source (Ocean Optics Inc., Dunedim, FL, USA). Based on the values of reflectance at $705 \mathrm{~nm}\left(\mathrm{R}_{705}\right)$ and $750 \mathrm{~nm}\left(\mathrm{R}_{750}\right)$, the normalized difference reflectance index was calculated as $N D_{705}=\left(R_{750}-R_{705}\right) /\left(R_{750}+R_{705}\right)$ (Gitelson \& Merzlyak 1994). We performed one measurement per leaf for each device. Measurements were always performed in the same place, at the middle of the leaf blade. After absorbance and reflectance measurements, leaves were digitalized with an HP 2400 scanner. The digitalized images were saved in a TIFF format and the LAs were calculated using the ImageJ software (http://rsb.info.nih.gov/ij/). Then, three leafdiscs (6 mm diameter) were collected from the same area where the absorbance and reflectance measurements were taken. The leaf discs were placed in Eppendorf tubes with $5 \mathrm{~mL}$ dimethyl sulfoxide (DMSO) saturated with $\mathrm{CaCO}_{3}$ (Hiscox \& Israelstam 1979). The tubes were incubated at $65^{\circ} \mathrm{C}$ for $24 \mathrm{~h}$, for the total extraction of leaf pigments. An aliquot of $3 \mathrm{ml}$ of the extract was used to measure the pigment absorbance at $649 \mathrm{~nm}$ and $665 \mathrm{~nm}$, using a V$1100 D^{\oplus}$ spectrophotometer (Mesu Lab Enterprise Co., Ltd, China). Chl $a$ and $b$ contents were calculated according to Wellburn (1994). Finally, the leaves were dried at $65^{\circ} \mathrm{C}$ until a constant mass. The dry mass and the leaf area were used for the calculation of LMA for each individual leaf.

Parameters of the homographic model 
Tab. 2 - Average leaf area (LA), leaf mass per area (LMA) and contents of chlorophyll $a(\mathrm{Chl} a), b(\mathrm{Chl} b)$ and total (Chl $t)$ of the seedlings of six Neotropical rainforest tree species.

\begin{tabular}{|c|c|c|c|c|c|c|}
\hline Species & $\mathrm{n}$ & $\begin{array}{c}\mathrm{LA} \\
\left(\mathrm{cm}^{2}\right)\end{array}$ & $\begin{array}{c}\text { LMA } \\
\left(\mathrm{g} \mathrm{m}^{2}\right)\end{array}$ & $\begin{array}{c}\mathrm{Chl} a \\
\left(\mathrm{mg} \mathrm{m}^{-2}\right)\end{array}$ & $\begin{array}{c}\text { Chl b } \\
\left(\mathrm{mg} \mathrm{m}^{-2}\right)\end{array}$ & $\begin{array}{c}\text { Chl } t \\
\left(\mathrm{mg} \mathrm{m}^{-2}\right)\end{array}$ \\
\hline B. rubescens & 35 & $29.5 \pm 9.5$ & $69.0 \pm 8.6$ & $270.1 \pm 126.4$ & $141.5 \pm 68.3$ & $411.6 \pm 194.4$ \\
\hline C. brasiliense & 32 & $19.1 \pm 3.7$ & $98.9 \pm 21.4$ & $162.6 \pm 71.0$ & $89.4 \pm 32.8$ & $252.0 \pm 103.0$ \\
\hline C. myrianthum & 36 & $14.6 \pm 3.9$ & $34.8 \pm 8.7$ & $98.1 \pm 57.9$ & $44.2 \pm 25.1$ & $142.3 \pm 82.8$ \\
\hline E. macrophylla & 37 & $22.8 \pm 6.6$ & $61.4 \pm 6.0$ & $102.4 \pm 60.6$ & $58.4 \pm 33.9$ & $160.8 \pm 94.3$ \\
\hline I. capitata & 30 & $17.2 \pm 5.2$ & $90.8 \pm 14.3$ & $180.4 \pm 90.8$ & $90.3 \pm 44.5$ & $270.7 \pm 134.7$ \\
\hline T. guianensis & 30 & $14.2 \pm 3.8$ & $55.5 \pm 8.0$ & $160.6 \pm 72.1$ & $106.6 \pm 39.8$ & $267.1 \pm 111.4$ \\
\hline
\end{tabular}

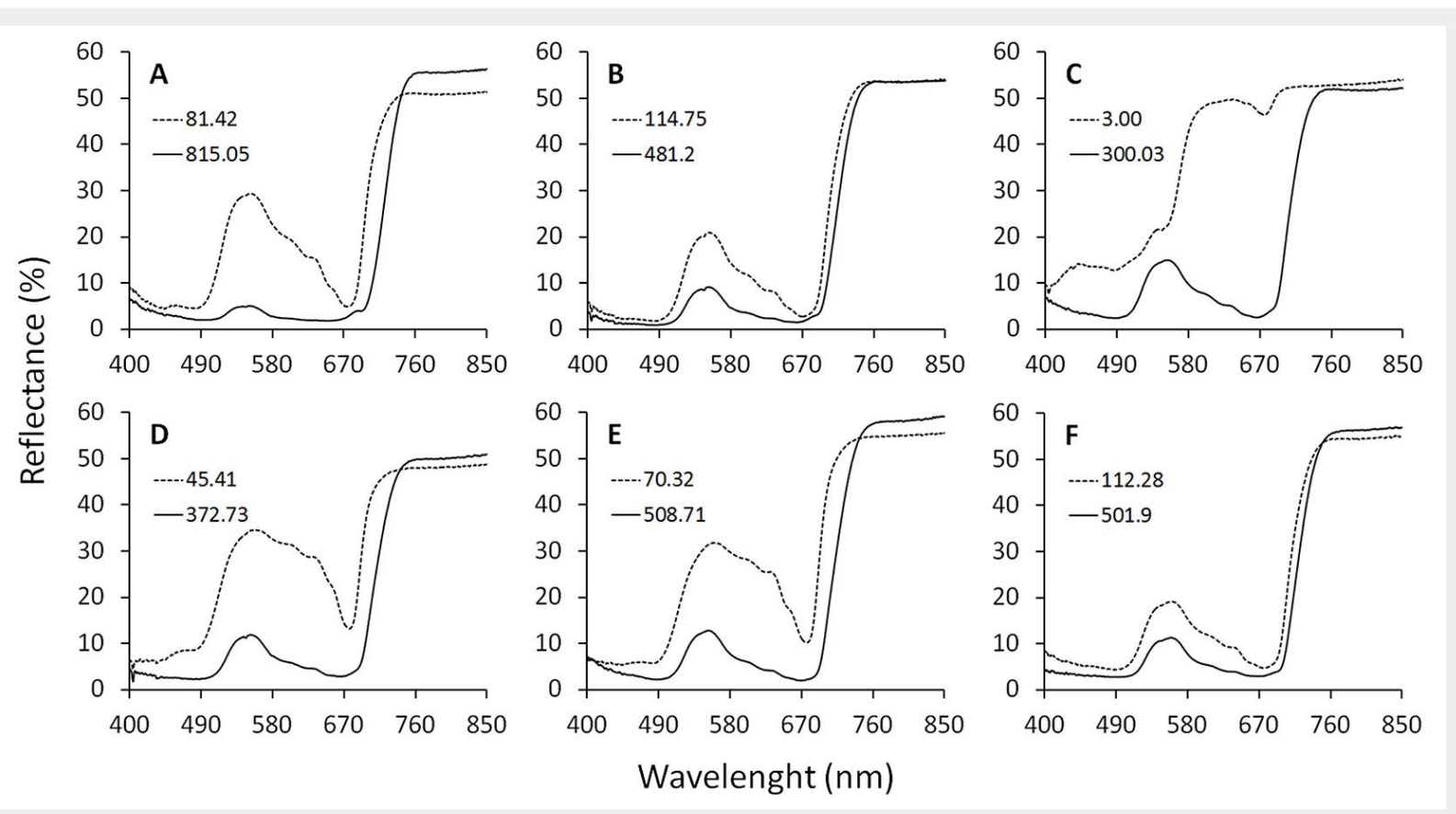

Fig. 1 - Spectral properties of seedlings of six Neotropical rainforest tree species. The percentage of the irradiance reflected by the adaxial leaf surface was obtained with a spectrometer USB400o-UV-VIS using a LS-1 tungsten-halogen light source (Ocean Optics Inc. Dunedim, FL, USA). Dotted and continuous lines correspond to the lowest and the highest values of total chlorophyll content $\left(\mathrm{mg} \mathrm{m}^{-2}\right)$ for single-leaf measurements of each species, respectively, determined by dimethyl sulfoxide extraction and spectrophotometric measurements. (A): B. rubescens; (B): C. brasiliense; (C): C. myrianthum; (D): E. macrophylla; (E): I. capitata; (F): T. guianensis.

$\mathrm{Chl}=(\alpha \cdot$ index $) /(\beta-$ index $)$ (Coste et al. 2010) were calibrated for chlorophyll contents (Chl $a, b$, and $t$ ) and chlorophyll indices $\left(\mathrm{ND}_{705}, \mathrm{FCl}\right.$ and SPADi) using the entire data set $(n=200)$. The relative root mean square calibration errors $\left(\mathrm{RMS}_{\mathrm{c}}, \%\right)$ were calculated for each of the six rainforest tree species cited in Tab. $1(n=30-37)$, based on chlorophyll values estimated by the multi-species models and on the chlorophyll values measured by the indices. $R M S \varepsilon_{c}$ was used as an indicator of the accuracy of predictive models and as a comparison with data from the literature ( $\mathrm{Ri}$ chardson et al. 2002).

\section{Results}

The average values for LA among the studied species ranged between 14.2 and $29.5 \mathrm{~cm}^{2}$, and for LMA, values ranged within 34.8 and $98.9 \mathrm{~g} \mathrm{~m}^{-2}$ (Tab. 2). The lowest and highest values for LA and LMA were found in $T$. guianensis and $B$. rubescens, and in C. myriantum and C. brasiliense, respectively. The average chloro- phyll content obtained via traditional anthum and B. rubescens, respectively. The DMSO extraction methods ranged be- lower and higher individual values of $\mathrm{Chl} t$ tween $142.3-411.6 \mathrm{mg} \mathrm{m}^{-2}$ for $\mathrm{Chl} t$, 98.1- contents for each of the six species used in $270.1 \mathrm{mg} \mathrm{m}^{-2}$ for $\mathrm{Chl} a$, and $44.2-141.5 \mathrm{mg} \mathrm{m}^{-2}$ this study are represented by the spectral for $\mathrm{Chl} b$. The lowest and highest mean val- properties of the leaves in Fig. 1.

ues for $\mathrm{Chl} t, b$, and $a$ were found in C. myri- A strong linear relationship was observed

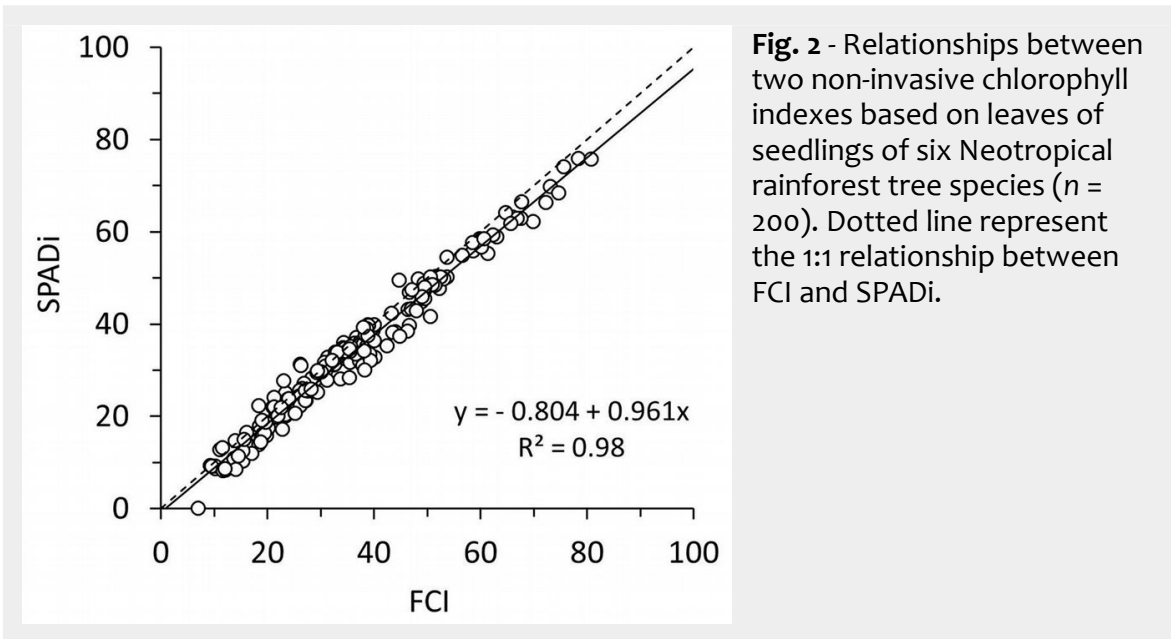


Fig. 3 - Relationships between chlorophyll

contents and noninvasive chlorophyll in-

dexes. Parameters of the homographic models based on leaves of seedlings of six Neotropical rainforest tree species ( $n$ $=200)$ are shown in Tab. 3.
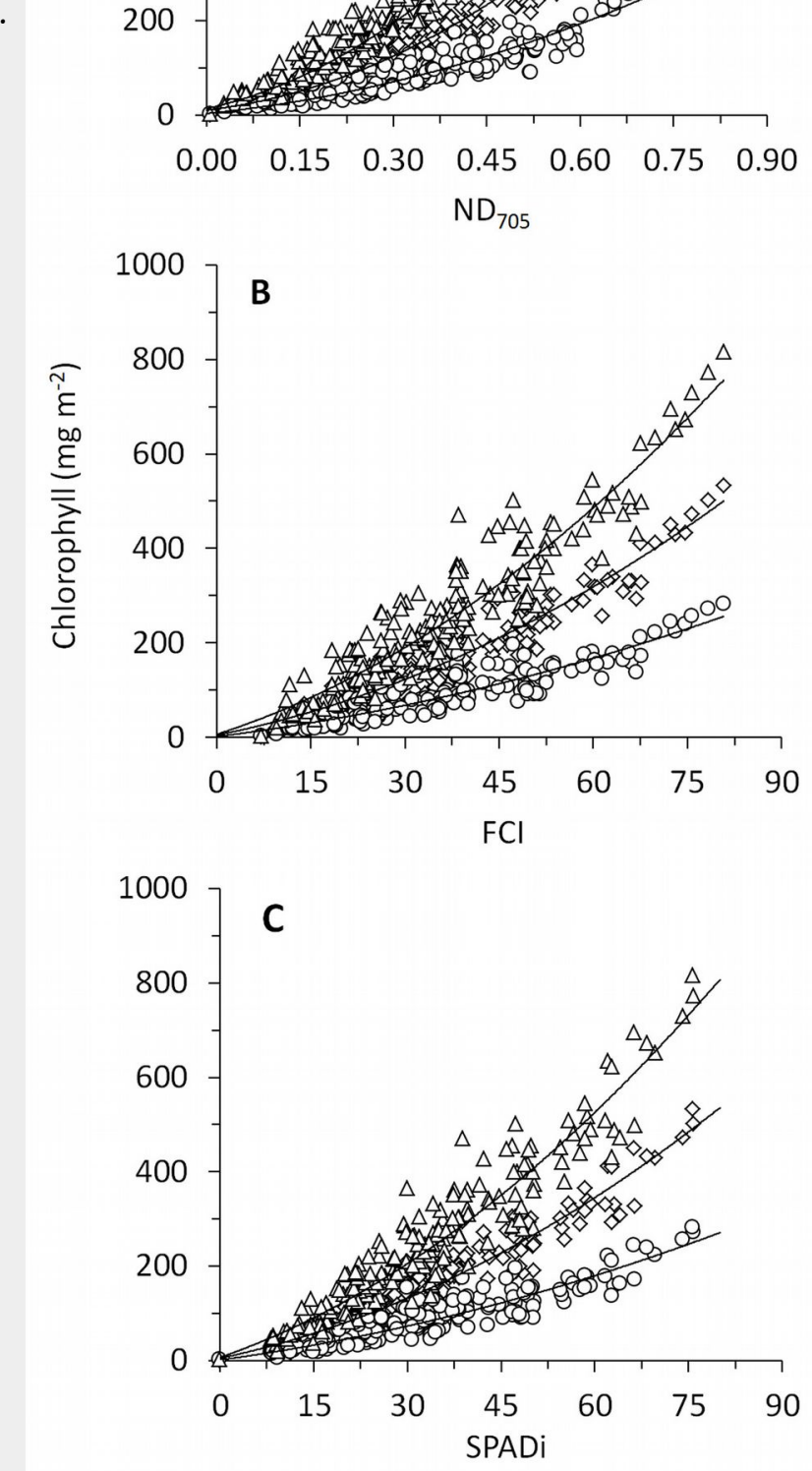

Tab. 3 - Parameters of the homographic model $\mathrm{Chl}=(\alpha \cdot$ index $) /(\beta$ - index $)$ for relationships between non-invasive chlorophyll indexes and chlorophyll contents based on leaves of seedlings of six Neotropical rainforest tree species $(n=200)$.

\begin{tabular}{llrrc}
\hline Index & Chl & $\boldsymbol{\alpha}$ & $\boldsymbol{\beta}$ & $\boldsymbol{R}^{2}$ \\
\hline $\mathrm{ND}_{705}$ & $\mathrm{Chl} a$ & 515.04 & 1.45 & 0.95 \\
& $\mathrm{Chl} b$ & 337.71 & 1.67 & 0.86 \\
& $\mathrm{Chl} t$ & 841.97 & 1.52 & 0.93 \\
$\mathrm{FCl}$ & $\mathrm{Chl} a$ & 647.94 & 183.98 & 0.91 \\
& $\mathrm{Chl} b$ & 417.25 & 211.20 & 0.82 \\
& $\mathrm{Chl} t$ & 1053.44 & 191.88 & 0.89 \\
SPADi & $\mathrm{Chl} a$ & 690.35 & 181.89 & 0.92 \\
& $\mathrm{Chl} b$ & 458.52 & 214.23 & 0.83 \\
& $\mathrm{Chl} t$ & 1132.38 & 191.07 & 0.90 \\
\hline
\end{tabular}

between the two handheld chlorophyll meters, suggesting that data obtained from Clorofilog $(\mathrm{FCl})$ can be easily converted into SPADi (Fig. 2). Relationships between chlorophyll content and the nondestructive methods tested in this study were all curvilinear (Fig. 3) and the $R^{2}$ values obtained for the calibrated homographic models were above 0.8 (Tab. 3). For all methods, the highest values of $R^{2}$ were observed for $\mathrm{Chl} a$, followed by $\mathrm{Chl} t$ and $b$. Although the $R^{2}$ values were very similar among the three methods, the best fit was obtained for the data from $\mathrm{ND}_{705}\left(R^{2} \geq 0.86\right)$ followed by SPAD-502 $\left(R^{2} \geq 0.83\right)$, and ClorofiLog $\left(R^{2} \geq 0.82\right)$.

For all species and indices, the calculated values of RMS $\varepsilon_{c}$ were below $20 \%$ (Tab. 4). Among species, the lowest values of RMS $\varepsilon_{c}$ were observed in $C$. myrianthum and $E$. macrophylla, whereas the highest value of $R M S \varepsilon_{c}$ was found in $T$. guianensis. The $\mathrm{ND}_{705}$ index had the lowest average $R M S \varepsilon_{c}$ values for Chl $t, a$, and $b$, followed by SPADi and $\mathrm{FCl}$. The lowest and highest values of $\mathrm{RMS} \varepsilon_{\mathrm{c}}$ for $\mathrm{Chl} a$ and $b$ were found in C. myrianthum and $\mathrm{E}$. macrophylla $\left(\mathrm{ND}_{705}\right)$, and $\mathrm{T}$. guianensis $(\mathrm{FCl})$, respectively. The lowest and highest values of $\mathrm{RMS}_{\mathrm{c}}$ for $\mathrm{Chl} t$ were found in E. macrophylla $\left(\mathrm{ND}_{705}\right)$ and T. guianensis $(\mathrm{FCl})$, respectively.

\section{Discussion}

The results from our study show that the homographic model proposed by Coste et al. (2010) is suitable for calibration of the relationship between absolute chlorophyll content and the chlorophyll indices $\mathrm{ND}_{705}$, $\mathrm{SPADi}$, and $\mathrm{FCl}$. As expected, there is a tendency towards a non-linear relationship between chlorophyll content and the chlorophyll indices (Richardson et al. 2002, Sims \& Gamon 2002, Uddling et al. 2007). The nonlinear response may reflect the physical limitation of optical methods at higher chlorophyll concentrations (Markwell et al. 1995, Steele et al. 2008, Schlemmer et al. 2013), and the non-uniform distribution of chlorophyll in the leaf blade, particularly when there is high chlorophyll density in chloroplasts (Casa et al. 2015). Nonetheless, good fits can be obtained for Chl $a\left(R^{2}\right.$ $\geq 0.91), t\left(R^{2} \geq 0.89\right)$, and $b\left(R^{2} \geq 0.82\right)$. A greater fit was observed for Chl $a$ in all indices, which is particularly important because $\mathrm{Chl} a$ is always present in a greater amount than $\mathrm{Chl} b$ in the light harvesting complexes, thus having a significant contribution to Chl $t$ (Nobel 2009).

Both handheld chlorophyll meters used in the present study operate in a similar way, with small differences. Although SPAD-502 measures absorption from leaves at two wavelengths, $660 \mathrm{~nm}$ (red) and $940 \mathrm{~nm}$ (near-infrared), Clorofilog measures the absorption at three wavelengths, $635 \mathrm{~nm}$ and $660 \mathrm{~nm}$ (red) and $880 \mathrm{~nm}$ (near infrared - Barbosa et al. 2013, Rigoni et al. 2013). We expected ClorofiLog, which measures a third wavelength near the second absorption peak of $\mathrm{Chl} \mathrm{b}(642 \mathrm{~nm})$, to provide 
Tab. 4 - Relative root mean square calibration errors (RMS $\varepsilon_{c}$, \%) based on the estimated chlorophyll values by the multi-species models (Tab. 3, $n=200$ ) and measured values for seedlings of six Neotropical rainforest tree species.

\begin{tabular}{llrrr}
\hline Species & Chl & ND $_{705}$ & FCl & SPADi \\
\hline B. rubescens & Chl $a$ & 8.2 & 6.7 & 6.6 \\
$(n=35)$ & Chl $b$ & 10.0 & 7.7 & 8.1 \\
& Chl $t$ & 8.6 & 6.7 & 6.8 \\
\hline C. brasiliense & Chl $a$ & 4.8 & 6.2 & 4.2 \\
$(n=32)$ & Chl $b$ & 7.5 & 6.8 & 5.4 \\
& Chl $t$ & 5.5 & 6.0 & 4.0 \\
\hline C. myrianthum & Chl $a$ & 2.4 & 5.0 & 4.4 \\
( $n=36)$ & Chl $b$ & 6.4 & 5.9 & 5.4 \\
& Chl $t$ & 3.0 & 4.5 & 3.8 \\
E. macrophylla & Chl $a$ & 3.1 & 4.9 & 3.7 \\
( $n=37)$ & Chl $b$ & 3.2 & 5.0 & 4.9 \\
& Chl $t$ & 2.9 & 4.8 & 4.0 \\
\hline I. capitata & Chl $a$ & 7.5 & 10.2 & 11.5 \\
( $n=30)$ & Chl $b$ & 10.9 & 12.9 & 14.0 \\
& Chl $t$ & 8.3 & 11.0 & 12.2 \\
\hline T. guianensis & Chl $a$ & 7.2 & 10.9 & 9.5 \\
(n=30) & Chl $b$ & 14.8 & 18.7 & 17.2 \\
& Chl $t$ & 9.7 & 13.5 & 12.0 \\
\hline
\end{tabular}

greater accuracy for chlorophyll estimates. However, the values of $R^{2}$ and $R M S \varepsilon_{c}$ for both devices were similar, which means that SPAD-502 and ClorofiLog provide equally accurate chlorophyll estimates. Additionally, the indices provided by these devices ( $\mathrm{FCl}$ and SPADi) showed a strong linear relationship. This result has an important application. Most regression models available in the current literature predicting chlorophyll content in tropical trees have been developed using SPAD-502 (Marenco et al. 2009, Coste et al. 2010, Mielke et al. 2010). ClorofiLog is newer and is currently being used more frequently in some countries. Based on the results from our study, the data from ClorofiLog can now be safely converted to the SPAD index and used for the estimation of chlorophyll content using regression with the models already available in literature (Marenco et al. 2009, Coste et al. 2010, Mielke et al. 2010).

The $\alpha$ parameter of the model described by Coste et al. (2010) for Chl $t$ (1.171 $\left.\mathrm{mg} \mathrm{m}^{-2}\right)$ was similar to values found in our study for both chlorophyll meters, but the value of $\beta$ (148.84) was lower than the values found in our study. Compared with the model reported by Coste et al. (2010), our model would result in an underestimation of the chlorophyll content as the SPADi values increase. We attribute these discrepancies to differences in the maximum values of chlorophyll contents. In the present study, the maximum value of $\mathrm{Chl} t$ was $815 \mathrm{mg} \mathrm{m}^{-2}$ (B. rubescens), while Coste et al. (2010) reported maximum values of $\mathrm{Chl} t$ around of $1500 \mathrm{mg} \mathrm{m}^{-2}$. The differences in chlorophyll content can be explained by differences in the ontogenetic stages of the plants, environmental conditions, and species used in the two studies. The plants used by Coste et al. (2010) were around 2 years old, whereas the plants used in the present study were 2-4-months old. Different studies have shown that seedlings of tropical trees have lower nitrogen and chlorophyll contents per leaf area unit than adults (Ishida et al. 2005, Houter \& Pons 2012). Differences in chlorophyll content can also be explained by the distinct environmental conditions in which plants are grown. In the present study, seedlings were grown in nursery conditions, under $50 \%$ of full sun, whereas the plants studied by Coste et al. (2010) were grown under three different light treatments: $5 \%, 10 \%$, and $20 \%$ full sun. The reduction in light intensity induces an increase in chlorophyll content of leaves (Nobel 2009), which may explain the higher chlorophyll content reported in the study of Coste et al. (2010). Although the maximum values of $\mathrm{Chl} t$ found in the present study were lower than the values reported by Coste et al. (2010), they are in agreement with values reported for other tropical trees, for instance, Scleronema micranthum (600 mg $\mathrm{m}^{-2}$ ), Swietenia macrophylla, and Ceiba pentandra (900 $\mathrm{mg} \mathrm{m}^{-2}$ - Marenco et al. 2009). Additionally, the $\beta$ values calculated individually for each of the 13 species ranged from 88.2 (Cecropia obtusa) to 299.2 (Eperua falcata), with a large dispersion of data in the SPADi range between 40 and 60 , and chlorophyll content between 500 and 1000 $\mathrm{mg} \mathrm{m}^{-2}$ (Coste et al. 2010). Based on this, the model proposed by Coste et al. (2010) can be applied to different indices and equipment, but the range of chlorophyll contents should be taken into account.

The average $R M S \varepsilon_{c}$ value calculated individually for each species is low compared with the values available in literature (Richardson et al. 2002, Coste et al. 2010, Mielke et al. 2012), indicating the high accuracy of our models. The average values of $\mathrm{RMS} \varepsilon_{\mathrm{c}}$ for Chl $a, b$, and $t$ in the present study were lower than $10 \%$. Richardson et al. (2002), for example, reported values of $\mathrm{RMS} \varepsilon_{\mathrm{c}}$ for $\mathrm{ND}_{705}$ varying from $11.9 \%$ (Chl $a$ ) to $15.2 \%(\mathrm{Chl} b)$, and values of $\mathrm{RMS} \varepsilon_{\mathrm{c}}$ for SPADi from $15.6 \%(\mathrm{Chl} b)$ to $20.3 \%(\mathrm{Chl} a)$. The RMSEc values lower than $10 \%$ prove the feasibility of the multi-species model for estimating Chl $a$ and $b$ from hand-held absorbance chlorophyll meters and leaf reflectance. Our highest value of $R M S \varepsilon_{c}$ was obtained for the estimation of $\mathrm{Chl} b$ in $T$. guianensis (18.7\%). Yet, this value is similar to those reported by Richardson et al. (2002) for estimates of Chl $b$ in Betula papyrifera, using different hand-held chlorophyll meters and leaf reflectance indices (14.6\% to $36.2 \%)$. It was also similar to values of RMSE $\varepsilon_{\text {c }}(14.6 \%$ to $29.2 \%)$ calculated by models based on reflectance indices in Eugenia uniflora by Mielke et al. (2012).

Neotropical rainforests are recognized for their high biodiversity (Martini et al. 2007) and increasing human pressures. The growth of human populations and changes in land use are the main causes of forest degradation and losses of biodiversity. Sustainable use of forest remnants and restoration of degraded forest ecosystems are challenges for scientists and civil organizations in the tropics (Chazdon 2008). Therefore, the suitability of scientific technology for the improvement the production and plantation of seedlings of native tree species is crucial to the success of commercial forest plantations and ecosystems restoration programs (Grossnickle 2012, Campoe et al. 2014). In the present study, we showed the feasibility of the multi-species model proposed by Coste et al. (2010) to estimate leaf chlorophyll content with the use of different instruments, aiming the application at seedling production in forest nurseries and monitoring the physiological performance of seedlings after introduction to reforestation areas. All indices tested in the present study showed excellent fits for $\mathrm{Chl} t, b$, and for $\mathrm{Chl} a$ in particular. We also demonstrated that the SPADi and FCI indices can be safely interconverted.

\section{Acknowledgements}

The authors thank Gerson J. Sales Neto, Nilson A. dos Santos, and Rones F. Souza of Floresta Viva Institute, and M.Sc. Murilo F. C. de Jesus for assistance with data collection. We thank Dr. Fábio P. Gomes of DCB/UESC for providing the SPAD-502 used in this study. Funding for Daniela V. Silva during this study was provided by a scholarship from Capes (Brazilian Higher Education Council). Marcelo S. Mielke and Ediófila Brito-Rocha gratefully acknowledge fellowships provided by CNPq (Brazilian National Council for Scientific and Technological Development). This study was supported by CNPq (Proc. 561933/2010).

\section{References}

Barbosa RH, Tabaldi LA, Miyazaki FR, Pilecco M, Kassab SO, Bigaton D (2013). Foliar copper uptake by maize plants: effects on growth and yield. Ciência Rural 43: 1561-1568. - doi: 10.1590/S0103-84782013000900005 Blackburn GA (2007). Hyperspectral remote sensing of plant pigments. Journal of Experimental Botany 58: 855-867. - doi: 10.1093/jxb/ 
erl123

Campoe OC, Iannelli C, Stape JL, Cook RL, Mendes JCT, Vivian R (2014). Atlantic forest tree species responses to silvicultural practices in a degraded pasture restoration plantation: From leaf physiology to survival and initial growth. Forest Ecology and Management 313: 233-242. - doi: 10.1016/j.foreco.2013.11.016

Casa R, Castaldi F, Pascucci S, Pignatti S (2015). Chlorophyll estimation in field crops: an assessment of handheld leaf meters and spectral reflectance measurements. Journal of Agriculture Science 153: 876-890. - doi: 10.1017/So0218 59614000483

Cate TM, Perkins TD (2003). Chlorophyll content monitoring in sugar maple (Acer saccharum). Tree Physiology 23: 1077-1079. - doi: 10.1093/ treephys/23.15.1077

Chazdon RL (2008). Beyond deforestation: restoring forests and ecosystems services on degraded lands. Science 320: 1459-1460. - doi: 10.1126/science. 1155365

Costa-Azevedo GF (2014). Photosynthetic parameters and growth in seedlings of Bertholletia excelsa and Carapa guianensis in response to pre-acclimation to full sunlight and mild water stress. Acta Amazonica 44: 67-78. - doi: 10.1590/ S0044-59672014000100007

Coste S, Baraloto C, Leroy C, Marcon E, Renaud A, Richardson AD, Roggy JC, Schimann H, Uddling J, Hérault B (2010). Assessing foliar chlorophyll contents with the SPAD-502 chlorophyll meter: a calibration test with thirteen tree species of tropical rainforest in French Guiana. Annals of Forest Science 67: 303-310. - doi: $10.1051 /$ forest/2010020

Gamon JA, Surfus JS (1999). Assessing leaf pigment content and activity with a reflectometer. New Phytologist 143: 105-117. - doi: 10.1046/j.146 9-8137.1999.00424.x

Gitelson AA, Merzlyak MN (1994). Spectral reflectance changes associate with autumn senescence of Aesculus hippocastanum L. and Acer platanoides L. leaves. Spectral features and relation to chlorophyll estimation. Journal of Plant Physiology 143: 286-292. - doi: 10.1016/S0176-1617(11)81633-0

Grace J, Nichol C, Disney M, Lewis P, Quaife T, Bowyer $P$ (2007). Can we measure terrestrial photosynthesis from space directly, using spectral reflectance and fluorescence? Global Change Biology 13: 1484-1497. - doi: 10.1111/j.136 5-2486.2007.01352.x

Grossnickle SC (2012). Why seedlings survive: influence of plant attributes. New Forests 43: 711-738. - doi: 10.1007/s11056-012-9336-6

Hawkins TS, Gardiner ES, Comer GS (2009). Modeling the relationship between extractable chlorophyll and SPAD-502 readings for endan- gered plant species research. Journal for Nature Conservation 17: 123-127. - doi: 10.1016/j.jnc. 2008.12.007

Hiscox JD, Israelstam GE (1979). A method for the extraction of chlorophyll from leaf tissue without maceration. Canadian Journal of Botany 57: 1332-1334. - doi: 10.1139/b79-163

Houter NC, Pons TL (2012). Ontogenetic changes in leaf traits of tropical rainforest trees differing in juvenile light requirement. Oecologia 169: 33-45. - doi: 10.1007/s00442-011-2175-x

Ishida A, Yazaki K, Hoe AL (2005). Ontogenetic transition of leaf physiology and anatomy from seedlings to mature trees of a rain forest pioneer tree, Macaranga gigantea. Tree Physiology 25: 513-522. - doi: 10.1093/treephys/25.5.513

Kitajima K, Hogan KP (2003). Increases of chlorophyll $\mathrm{a} / \mathrm{b}$ ratios during acclimation of tropical woody seedlings to nitrogen limitation and high light. Plant, Cell and Environment 26: 857865. - doi: 10.1046/j.1365-3040.2003.01017.x Kokaly RF, Asner GP, Ollinger SV, Martin ME, Wessman CA (2009). Characterizing canopy biochemistry from imaging spectroscopy and its application to ecosystem studies. Remote Sensing Environment 113: S78-S91. - doi: 10.1016/ j.rse.2008.10.018

Lichtenthaler HK (1987). Chlorophylls and carotenoids: pigment photosynthetic biomembranes. Methods in Enzymology 148: 362-385. doi: 10.1016/0076-6879

Marenco RA, Antezana-Vera SA, Nascimento HCS (2009). Relationship between specific leaf area, leaf thickness, leaf water content and SPAD-502 readings in six Amazonian tree species. Photosynthetica 47: 184-190. - doi: 10.1007/ s11099-009-0031-6

Markwell J, Osterman JC, Mitchell JL (1995). Calibration of the Minolta SPAD-502 leaf chlorophyll meter. Photosynthesis Research 46: 467472. - doi: 10.1007/BFo0032301

Martini AMZ, Fiaschi P, Amorim AM, Paixão JLD (2007). A hot-point within a hotspot: a high diversity site in Brazil's Atlantic Forest. Biodiversity and Conservation 16: 3111-3128. - doi: 10.1007/s10531-007-9166-6

Mielke MS, Schaffer B, Li C (2010). Use of a SPAD meter to estimate chlorophyll content in Eugenia uniflora $\mathrm{L}$. leaves as affected by contrasting light environments and soil flooding. Photosynthetica 48: 332-338. - doi: 10.1007/s11099-0100043-2

Mielke MS, Schaffer B, Schilling AC (2012). Evaluation of reflectance spectroscopy indices for estimation of chlorophyll content in leaves of a tropical tree species. Photosynthetica 50: 343352. - doi: 10.1007/s11099-012-0038-2

Nobel P (2009). Physicochemical and environmental plant physiology. Academic Press, S.
Diego, CA, USA, pp. 600

Pettorelli N, Vik JO, Mysterud A, Gaillard JM, Tucker CJ, Stenseth NC (2005). Using the satellite-derived NDVI to assess ecological responses to environmental change. Trends in Ecology and Evolution 20: 503-510. - doi: 10.1016/j.tree.2005.05.011

Pinkard EE, Patel V, Mohammed C (2006). Chlorophyll and nitrogen determination for plantation-grown Eucalyptus nitens and E. globulus using a non-destructive meter. Forest Ecology and Management 223: 211-217. - doi: 10.1016/j.for eco.2005.11.003

Richardson AD, Duigan SP, Berlyn GP (2002). An evaluation of noninvasive methods to estimate foliar chlorophyll content. New Phytologist 153: 185-194. - doi: 10.1046/j.0028-646X.2001.0028 9. $\mathrm{x}$

Rigoni JPG, Capuani S, Brito-Neto JF, Beltrão NEM (2013). Indirect measurement of photosynthetic pigments in the leaves of Jatropha curcas. Semina: Ciências Agrárias 34: 669-674. doi: 10.5433/1679-0359.2013v34n2p669

Schlemmer M, Gitelson A, Schepers J, Ferguson R, Peng Y, Shanahan J, Rundquist D (2013). Remote estimation of nitrogen and chlorophyll contents in maize at leaf and canopy levels. International Journal of Applied Earth Observation and Geoinformation 25: 47-54. - doi: 10.1016/j.jag.2013.04.003

Sims DA, Gamon JA (2002). Relationships between leaf pigment content and spectral reflectance across a wide range of species, leaf structures and developmental stages. Remote Sensing of Environment 81: 337-354. - doi: 10.1016/S0034-4257(02)00010-X

Steele MR, Gitelson AA, Rundquist DCA (2008). Comparison of two techniques for nondestructive measurement of chlorophyll content in grapevine leaves. Agronomy Journal 100: 779782. - doi: 10.2134/agronj2007.0254N

Uddling J, Gelang-Alfredsson J, Piikki K, Pleijel H (2007). Evaluating the relationship between leaf chlorophyll concentration and SPAD-502 chlorophyll meter readings. Photosynthesis Research 91: 37-46. - doi: 10.1007/s11120-006-90775

Van Den Berg AK, Perkins TD (2004). Evaluation of a portable chlorophyll meter to estimate chlorophyll and nitrogen contents in sugar maple (Acer saccharum Marsh.) leaves. Forest Ecology and Management 200: 113-117. - doi: 10.1016/j.foreco.2004.06.005

Wellburn AR (1994). The spectral determination of chlorophylls $a$ and $b$, as well as total carotenoids, using various solvents with spectrophotometers of different resolution. Journal of Plant Physiology 144: 307-313. - doi: 10.1016/So1 76-1617(11)81192-2 